\title{
Potato Resistance to Cucumber Mosaic Virus is Temperature Sensitive and Virus- Strain Specific
}

\author{
Fevziye Celebi-Toprak ${ }^{* 1,2,3)}$, Steven A. Slack ${ }^{1,4)}$ and Patrick Russo ${ }^{5)}$ \\ 1) Department of Plant Pathology, Cornell University, Ithaca, NY 14853, USA \\ 2) Department of Biology, Pamukkale University, Kinikli, Denizli, 20010, Turkey \\ 3) Gene Research Center, University of Tsukuba, 1-1-1 Tennoudai, Tsukuba, Ibaraki 305-8572, Japan \\ 4) Ohio Agricultural Research and Development Center, Ohio State University, Wooster, OH 44691, USA \\ 5) Luganskaya 9 PO Box 25115516 Moscow Russian Federation
}

\begin{abstract}
Cucumber mosaic virus (CMV) is an important plant pathogen worldwide, which infects and causes yield losses to many solanaceous crops but rarely to potatoes. In the study reported here, we have tested the susceptibility of various potato genotypes to three different CMV strains, Pf-CMV and Fny-CMV, which belong to subgroup I, and A9-CMV, a member of subgroup II. Eight potato genotypes were found that could be systemically infected by at least one of the three CMV strains. Furthermore, although most potato cultivars were resistant to systemic infection at $24^{\circ} \mathrm{C}$, all became infected systemically when inoculated plants were grown at $30^{\circ} \mathrm{C}$. These results suggested that the natural resistance that most potato crops express to CMV might be overcome under high-temperature growing conditions following infection, and that CMV resistance in potato showed virus strain specificity.
\end{abstract}

Key Words: temperature, resistance, strains, CMVFny, CMV-Pf, CMV-A9.

\section{Introduction}

Cucumber mosaic virus (CMV) is the type member of the cucumovirus group (Palukaitis et al. 1992). Many strains of CMV have been identified and these are divided into two subgroups (I and II). The virus is transmitted both mechanically and by aphids in a non-persistent manner to a very broad range of hosts, including many agriculturally important crops in the family Solanaceae (e.g., tomato, pepper, and tobacco). With such a broad host range encompassing many crops and given the severity of the disease in these hosts, economic losses worldwide due to CMV can be measured in the billions of USD (Watterson 1993).

Though little progress has been made in identifying a source useful level of natural resistance to CMV in most solanaceous crops, potato (Solanum tuberosum L.) may pro-

Communicated by K. Watanabe

Received August 16, 2002. Accepted October 9, 2002.

*Corresponding author (e-mail: fctoprak@pamukkale.edu.tr) vide a unique opportunity. In contrast to other solanaceous crops, CMV has had little economic effect on potato crops (De Boks and van der Want 1987, Hooker 1981). It has been found that CMV can replicate in potato plants and spread short distances within an inoculated leaf, however, long distance systemic movement of CMV did not occur in most potato cultivars tested (Celebi et al. 1998). Thus, it appears that potato may have a natural mechanism to inhibit systemic infection by CMV, which could make potato a candidate for CMV resistance gene studies.

The first objective of this study was to test the breadth of resistance of potato to various CMV strains. In previous reports different CMV strains produced various symptoms and severity of infections in different plant species (Jones and Latham 1996, Roossinck and Palukaitis 1990, Valkonen et al. 1995). It has also been reported that different CMV strains caused varying degrees of symptom severity in the same test species. For example, in some susceptible squash cultivars, the Fny-CMV strain showed severe systemic symptoms 1-3 days post-inoculation (p.i.), whereas the SnyCMV strain showed mild systemic symptoms 5-7 days p.i. (Roossinck and Palukaitis 1990). Furthermore, Valkonen et al. (1995) reported CMV strain-specific symptoms in potatoes that were graft inoculated. Thus, as part of our study three CMV strains, Pf-CMV and Fny-CMV from subgroup I, and A9-CMV from subgroup II, were used to mechanically inoculate selected potato genotypes to test their response to inoculation.

In addition to viral strain-specific effects, environmental factors such as temperature have been observed to affect the resistance of certain plants to CMV. Previous reports have suggested that natural resistance to CMV observed in certain crops could be overcome when virus inoculated plants were grown at elevated temperatures (Nono-Womdim et al. 1991, Pink and Walkey 1985, Pound and Cheo 1952). In the few documented cases where cultivated potato crops were reported to be infected by CMV; potatoes, which are generally considered a cool weather crop, were being grown in warm climates such as central California during the summer months and Saudi Arabia (Shahwan et al. 1997, MacArthur 1958, Sangar and Agrawal 1986, Somerville et al. 1987). A more recent report (Valkonen and Watanabe 1999) showed that diploid potato plants, which were resistant 
to $\mathrm{CMV}$ when grown at lower temperatures $\left(18^{\circ} \mathrm{C}\right)$, became infected at higher growth temperatures $\left(28^{\circ} \mathrm{C}\right)$. Therefore, the second objective of this study was to test the temperature sensitivity of CMV resistance in different potato cultivars.

\section{Materials and Methods}

\section{Plants}

All potatoes were propagated from pathogen tested nuclear class tubers (courtesy of the Cornell Uihlein Farm, Lake Placid, NY) except for the genetic lines Acl7-8 and $2 \mathrm{x}(\mathrm{V}-3) 30$, which did not produce tubers at the NY state growing condition and therefore were planted from in vitro plantlets, obtained from our virus-tested stock collection. Some of the genotypes couldn't be tested with all strains because there were not available tubers and plantlets to be tested. Tobacco plants (Nicotiana tabacum L. cv. Samsun NN) were grown from seed and were used as controls in experiments.

\section{Virus Strains}

All CMV strains were obtained from Dr. P. Palukaitis (Dept. of Virology, Scottish Crop Research Institute). FnyCMV was originally isolated from muskmelon in New York, USA (Banik and Zitter 1990), and Pf-CMV was originally isolated from pepper in Florida, USA. Both strains belong to subgroup I. A9-CMV, which belongs to subgroup II, was isolated from Anemone coronaria in Italy during 1989. All CMV strains were maintained in tobacco cv. Samsun NN.

\section{Inoculations}

For all experiments, three to six young potato plants with approximately six leaves were mechanically inoculated. Inocula were prepared by extracting sap from infected tobacco leaves using a mechanical grinder, and diluting the sap $1: 10$ with phosphate buffer $\left(1.47 \mathrm{mM} \mathrm{KH}_{2} \mathrm{PO}_{4}, 8.1 \mathrm{mM}\right.$ $\mathrm{Na}_{2} \mathrm{HPO}_{4}$-anhydrous in 1 liter of $\mathrm{dH}_{2} \mathrm{O}, \mathrm{pH}$ 7.4). Inocula were kept on ice and used in 1 hour or less. Plants were inoculated by first lightly dusting plants with carborundum (mesh 250 to 400), and then applying inoculum with a cotton swab on the upper side of two leaves per plant. Two tobacco plants and two CMV susceptible potato cultivars were also inoculated during each experiment to act as positive controls. To serve as negative controls, two plants of each potato genotype and two tobacco plants were mock inoculated with phosphate buffer only. Two small holes were punched out of each inoculated leaf for identification.

\section{Virus Strain Comparison}

Eight potato genotypes were inoculated with Pf-CMV, 16 potato genotypes were inoculated with Fny-CMV, and 18 potato genotypes were inoculated with A9-CMV respectively. One day before and after inoculations, plants were shaded. Three to six plants of each genotype were inoculated with CMV per experiment, and each experiment was replicated two times. All plants were grown using a photoperiod of $16 \mathrm{~h}$.

\section{Temperature Differentials}

Potato genotypes were tested for susceptibility to Fny$\mathrm{CMV}$ when grown at $24^{\circ} \mathrm{C}$ or $30^{\circ} \mathrm{C}$. All plants were shaded for one day before and after mechanical inoculation. Since plants held continuously at $30^{\circ} \mathrm{C}$ developed neither local nor systemic infection, plants had to be placed at $24^{\circ} \mathrm{C}$ for one day before and after inoculation, and then grown at $30^{\circ} \mathrm{C}$ for the duration of the experiment. Three to six plants of each genotype were inoculated with CMV per experiment and the experiment was replicated two times.

\section{Assessments}

Plants were scored visually for symptoms and then samples were tested for virus by using the double antibody sandwich enzyme-linked immunosorbent assay (ELISA) of Clark and Adams (1977). Two separate samples were taken from plants two weeks after inoculation and tested separately for virus by ELISA. One sample came from inoculated leaves, the other came from leaves positioned two leaves above inoculated leaves. Additional samples consisting of uninoculated leaves from above the points of inoculation were taken four and eight weeks after inoculation and tested for virus by ELISA.

\section{Results}

At $24^{\circ} \mathrm{C}$ all potato genotypes tested appeared to support virus replication in inoculated leaves for CMV strains Pf, Fny and A9 (Table 1 and Table 2, and data not shown, respectively). In contrast, most of the potato genotypes were resistant to systemic infection by these CMV strains with notable exceptions (Table 1, Table2, and Table 3). For example, the genetic potato line Acl 7-8 was systemically infected by both Pf-CMV and A9-CMV, which represent subgroups I and II, respectively. Furthermore, although A6, Andover, Allegany, and the diploid potato $2 x(\mathrm{~V}-3) 30$ showed resistance to systemic infection by Pf-CMV, they were all systemically infected by another member of subgroup I, FnyCMV (Table 1 and Table 2). Potato cultivars Atlantic and All Blue were also systemically infected by Fny-CMV (Table 2), but resistant to A9-CMV (Table 3). The opposite response occurred for Katahdin, which was systemically infected by A9-CMV, but not by Fny-CMV. While symptoms and ELISA results did not change at four and eight weeks p.i. for Pf-CMV and Fny-CMV, certain potato genotypes did develop systemic infections by week eight to A9-CMV (Table 3). For example, though Allegany, Andover, and Katahdin tested negative for A9-CMV at four weeks, positive ELISA values were obtained eight weeks p.i.

Experiments that tested the temperature sensitivity of potato resistance to Fny-CMV showed that virus replicated in inoculated leaves of all potato cultivars tested whether plants were grown at 24 or $30^{\circ} \mathrm{C}$ p.i. (Table 4 and Table 5). From a total of 22 potato cultivars inoculated with Fny-CMV 
Table 1. Response of potatoes to mechanical inoculation with Pf-CMV

\begin{tabular}{lccccccc}
\hline \hline \multirow{2}{*}{ Potato Genotype } & \multicolumn{2}{c}{ Local Infection (inoculated leaves) } & & \multicolumn{3}{c}{ Systemic Infection (uninoculated leaves) } \\
\cline { 2 - 3 } & \% Infected & ELISA & SD $-/+$ & & \% Infected & ELISA & SD -/+ \\
\hline A6 & $100(6 / 6)$ & 1.21 & 0.160 & & $0(0 / 6)$ & 0.00 & 0.010 \\
Abnaki & $100(6 / 6)$ & 0.05 & 0.030 & & $0(0 / 6)$ & 0.01 & 0.009 \\
Allegany & $100(5 / 5)$ & 0.95 & 0.100 & & $0(0 / 5)$ & 0.02 & 0.002 \\
Andover & $50(3 / 6)$ & 0.44 & 0.100 & & $0(0 / 6)$ & 0.01 & 0.002 \\
NY99 & $100(3 / 3)$ & 0.13 & 0.010 & & $0(0 / 3)$ & 0.01 & 0.001 \\
Russet Burbank & $100(6 / 6)$ & 0.96 & 0.140 & & $0(0 / 6)$ & 0.02 & 0.001 \\
Acl 7-8 (tetraploid) & $100(5 / 5)$ & 0.87 & 0.050 & & $100(5 / 5)$ & 0.90 & 0.200 \\
2x (V-3) 30 (diploid) & $100(5 / 5)$ & 0.99 & 0.160 & & $0(0 / 5)$ & 0.01 & 0.001 \\
Tobacco+control & $100(2 / 2)$ & 1.20 & 0.050 & & $100(2 / 2)$ & 1.01 & 0.030 \\
Potato-control & $0(0 / 8)$ & 0.00 & 0.002 & & $0(0 / 8)$ & 0.01 & 0.002
\end{tabular}

ELISA values are means of samples taken 4 weeks post-inoculation. Numbers in parentheses denote the number of infected plants over number inoculated. Tobacco + control refers to plants mechanically inoculated with PfCMV. Potato - control refers to potato plants mock inoculated with phosphate buffer. SD stands for standard deviation.

Table 2. Response of potatoes to mechanical inoculation with Fny-CMV

\begin{tabular}{|c|c|c|c|c|c|c|}
\hline \multirow{2}{*}{ Potato Genotype } & \multicolumn{3}{|c|}{ Local Infection (inoculated leaves) } & \multicolumn{3}{|c|}{ Systemic Infection (uninoculated leaves } \\
\hline & $\%$ Infected & ELISA & $\mathrm{SD}-/+$ & $\%$ Infected & ELISA & $\mathrm{SD}-/+$ \\
\hline A6 & $100(6 / 6)$ & 1.79 & 0.060 & $100(6 / 6)$ & 1.26 & 0.340 \\
\hline Abnaki & $100(6 / 6)$ & 1.14 & 0.030 & $0(0 / 6)$ & 0.00 & 0.008 \\
\hline Allegany & $100(6 / 6)$ & 1.65 & 0.230 & $100(6 / 6)$ & 0.30 & 0.210 \\
\hline All Blue & $100(6 / 6)$ & 1.63 & 0.130 & $100(6 / 6)$ & 1.34 & 0.080 \\
\hline Andover & $100(6 / 6)$ & 0.68 & 0.210 & $100(6 / 6)$ & 0.25 & 0.120 \\
\hline Atlantic & $100(6 / 6)$ & 1.81 & 0.150 & $100(6 / 6)$ & 0.10 & 0.100 \\
\hline Amey & $100(6 / 6)$ & 1.13 & 0.400 & $0(0 / 6)$ & 0.00 & 0.004 \\
\hline Desiree & $100(6 / 6)$ & 1.05 & 0.400 & $0(0 / 6)$ & 0.00 & 0.020 \\
\hline La Rouge & $100(6 / 6)$ & 1.48 & 0.200 & $0(0 / 6)$ & 0.00 & 0.003 \\
\hline NY99 & $100(6 / 6)$ & 1.29 & 0.200 & $0(0 / 6)$ & 0.00 & 0.007 \\
\hline Katahdin & $100(6 / 6)$ & 1.33 & 0.300 & $0(0 / 6)$ & 0.00 & 0.010 \\
\hline Pentland Ivory & $100(6 / 6)$ & 1.32 & 0.300 & $0(0 / 6)$ & 0.00 & 0.001 \\
\hline Red LaSoda & $100(6 / 6)$ & 1.22 & 0.200 & $0(0 / 6)$ & 0.00 & 0.002 \\
\hline Russet Burbank & $100(6 / 6)$ & 1.33 & 0.290 & $0(0 / 6)$ & 0.00 & 0.003 \\
\hline 2x (V-2) 7 (diploid) & $100(6 / 6)$ & 0.11 & 0.150 & $0(0 / 6)$ & 0.01 & 0.001 \\
\hline 2x (V-3) 30 (diploid) & $100(6 / 6)$ & 0.25 & 0.100 & $100(6 / 6)$ & 0.13 & 0.040 \\
\hline Tobacco $(+)$ control & $100(2 / 2)$ & 1.32 & 0.160 & $100(2 / 2)$ & 1.65 & 0.020 \\
\hline Potato (-) control & $0(0 / 19)$ & 0.002 & 0.001 & $0(0 / 17)$ & 0.00 & 0.002 \\
\hline
\end{tabular}

ELISA values are means of samples taken 4 weeks post-inoculation. Numbers in parentheses denote the number of infected plants over number inoculated. Tobacco + control refers to plants mechanically inoculated with FnyCMV. Potato - control refers to potato plants mock inoculated with phosphate buffer. SD stands for standard deviation.

and grown at $24^{\circ} \mathrm{C}$ p.i., only six (A6, Allegany, All Blue, Andover, Atlantic, and diploid $2 \times(\mathrm{v}-3) 30)$ became systemically infected (Table 2 and Table 4$)$. In contrast, all 18 potato cultivars (17 from the original 22 genotypes plus cultivar Chippewa) that were inoculated with Fny-CMV and grown at $30^{\circ} \mathrm{C}$ p.i. developed systemic infections (Table 5). Furthermore, most potato genotypes grown at $30^{\circ} \mathrm{C}$ showed symptoms of CMV infection, which ranged from mild to severe mosaic, leaf deformation and stunted growth (Fig. 1).

\section{Discussion}

In this and previous studies (Celebi et al. 1998) it has been shown that $\mathrm{CMV}$ can replicate in potato plants, but the infection is usually localized to the leaf infected and does not spread to the rest of the plant. This phenomenon is probably the reason why $\mathrm{CMV}$ has not been a threat to most potato crops. At a growing temperature of $24^{\circ} \mathrm{C}$, most potato cultivars tested in this study were resistant to systemic CMV infection, though eight genotypes were susceptible to longdistance movement by at least one of the three CMV strains used in this study (Table 6). Thus, CMV resistance in potato is not absolute and appears to be genotype dependent. Furthermore, the genotypes that exhibit susceptibility to systemic CMV infection at $24^{\circ} \mathrm{C}$ also appear to show some CMV strain specificity (Table 6). Of the three CMV strains 
Table 3. Response of potatoes to mechanical inoculation with A9-CMV

\begin{tabular}{|c|c|c|c|c|c|c|}
\hline \multirow[t]{2}{*}{ Potato Genotype } & \multicolumn{3}{|c|}{$\begin{array}{l}4 \text { weeks Systemic Infection } \\
\text { (uninoculated leaves) }\end{array}$} & \multicolumn{3}{|c|}{$\begin{array}{l}8 \text { weeks Systemic Infection } \\
\text { (uninoculated leaves) }\end{array}$} \\
\hline & $\%$ Infected & ELISA & $\mathrm{SD}-/+$ & $\%$ Infected & ELISA & $\mathrm{SD}-/+$ \\
\hline Allegany & $0(0 / 5)$ & 0.00 & 0.003 & $20(1 / 5)$ & 0.11 & 0.040 \\
\hline All Blue & $0(0 / 5)$ & 0.01 & 0.006 & $0(0 / 5)$ & 0.00 & 0.001 \\
\hline Atlantic & $0(0 / 5)$ & 0.01 & 0.001 & $0(0 / 5)$ & 0.01 & 0.001 \\
\hline Amey & $0(0 / 5)$ & 0.00 & 0.003 & $0(0 / 5)$ & 0.00 & 0.001 \\
\hline Desiree & $0(0 / 7)$ & 0.00 & 0.001 & $0(0 / 7)$ & 0.02 & 0.003 \\
\hline La Rouge & $0(0 / 4)$ & 0.01 & 0.001 & $0(0 / 4)$ & 0.01 & 0.002 \\
\hline NY99 & $0(0 / 5)$ & 0.00 & 0.001 & $0(0 / 5)$ & 0.02 & 0.007 \\
\hline Katahdin & $0(0 / 5)$ & 0.01 & 0.003 & $60(3 / 5)$ & 0.20 & 0.100 \\
\hline Pentland Ivory & $0(0 / 3)$ & 0.00 & 0.002 & $0(0 / 3)$ & 0.02 & 0.003 \\
\hline Red LaSoda & $0(0 / 6)$ & 0.00 & 0.001 & $0(0 / 6)$ & 0.01 & 0.009 \\
\hline Russet Burbank & $0(0 / 5)$ & 0.00 & 0.002 & $0(0 / 5)$ & 0.00 & 0.002 \\
\hline 84.35 .7 (diploid) & $0(0 / 6)$ & 0.00 & 0.002 & $0(0 / 6)$ & 0.01 & 0.002 \\
\hline 85.37 .38 (diploid) & $0(0 / 3)$ & 0.00 & 0.001 & $0(0 / 3)$ & 0.01 & 0.009 \\
\hline 2x (V-2) 7 (diploid) & $0(0 / 3)$ & 0.01 & 0.001 & $0(0 / 3)$ & 0.02 & 0.001 \\
\hline 2x (V-3) 30 (diploid) & $0(0 / 4)$ & 0.00 & 0.001 & $0(0 / 4)$ & 0.02 & 0.006 \\
\hline Tobacco $(+)$ control & $100(2 / 2)$ & 1.02 & 0.020 & $100(2 / 2)$ & 1.55 & 0.030 \\
\hline Potato $(-)$ control & $0(0 / 19)$ & 0.00 & 0.002 & $0(0 / 17)$ & 0.00 & 0.002 \\
\hline
\end{tabular}

ELISA values are means of samples taken 4 and 8 weeks post-inoculation. Numbers in parentheses denote the number of infected plants over number inoculated. Tobacco + plants mechanically inoculated with A9-CMV, and potato - control refers to cultivars mock inoculated with phosphate buffer only. SD stands for standard deviation.

Table 4. Response of potato genotypes to Fny-CMV when grown at $24^{\circ} \mathrm{C}$ post-inoculation

\begin{tabular}{lccccccc}
\hline \multirow{2}{*}{ Potato Genotype } & \multicolumn{2}{c}{ Local Infection (inoculated leaves) } & & \multicolumn{3}{c}{ Systemic Infection (uninoculated leaves) } \\
\cline { 2 - 3 } & \% Infected & ELISA & SD -/+ & & \% Infected & ELISA & SD -/+ \\
\hline Abnaki & $100(6 / 6)$ & 1.64 & 0.002 & & $0(0 / 6)$ & 0.00 & 0.001 \\
Amey & $100(6 / 6)$ & 1.81 & 0.003 & & $0(0 / 6)$ & 0.00 & 0.004 \\
BelRus & $100(6 / 6)$ & 1.06 & 0.003 & & $0(0 / 6)$ & 0.00 & 0.002 \\
Castile & $100(6 / 6)$ & 1.07 & 0.002 & & $0(0 / 6)$ & 0.00 & 0.002 \\
Chieftain & $100(6 / 6)$ & 2.70 & 0.002 & & $0(0 / 6)$ & 0.01 & 0.002 \\
Kanona & $100(6 / 6)$ & 1.28 & 0.000 & & $0(0 / 6)$ & 0.01 & 0.001 \\
Katahdin & $100(6 / 6)$ & 1.43 & 0.001 & & $0(0 / 6)$ & 0.01 & 0.002 \\
La Rouge & $100(6 / 6)$ & 1.53 & 0.000 & & $0(0 / 6)$ & 0.00 & 0.002 \\
NY99 & $100(6 / 6)$ & 2.03 & 0.002 & & $0(0 / 6)$ & 0.01 & 0.002 \\
Pentland Ivory & $100(6 / 6)$ & 1.33 & 0.001 & & $0(0 / 6)$ & 0.01 & 0.003 \\
Russet Burbank & $100(6 / 6)$ & 1.06 & 0.001 & & $0(0 / 6)$ & 0.00 & 0.002 \\
Steuben & $100(6 / 6)$ & 1.83 & 0.002 & & $0(0 / 6)$ & 0.01 & 0.001 \\
Superior & $100(6 / 6)$ & 1.31 & 0.001 & & $0(0 / 6)$ & 0.00 & 0.001 \\
Tobacco+control & $100(2 / 2)$ & 1.32 & 0.002 & & $100(2 / 2)$ & 1.77 & 0.000 \\
Potato-control & $0(0 / 2)$ & 0.00 & 0.000 & & $0(0 / 2)$ & 0.01 & 0.002 \\
\hline
\end{tabular}

Local infection samples were taken from inoculated leaves 2 weeks post-inoculation, and systemic samples were taken from uninoculated leaves 4 weeks post-inoculation. All ELISA values are means, and numbers in parentheses denote the number of infected plants over number inoculated. Tobacco + control refers to tobacco plants inoculated with Fny-CMV, and potato - control refers to potato plants mock inoculated with phosphate buffer only. SD stands for standard deviation.

tested, Fny-CMV appears to be able to infect the broadest range of potato cultivars. However, Katahdin appeared resistant to systemic infection by Fny-CMV, though susceptible to the A9-CMV strain. None of these eight cultivars, however, were systemically infected by all three CMV strains at $24^{\circ} \mathrm{C}$. And, although Fny and Pf both belong to CMV subgroup I, potato cultivars A6, Allegany and Andover were only susceptible to Fny-CMV, and not Pf-CMV, while the reverse was true for genotype $2 \mathrm{x}(\mathrm{V}-3) 30$. This difference in systemic invasion between two strains from the same CMV subgroup has been observed previously in tobacco (Owen and Palukaitis 1988). In addition, Jones and Latham (1996) observed that different CMV strains of the same subgroup could produce different responses in lupin.

Another difference in host response was a delay in systemic infection. For example, Andover and Allegany were 
Table 5. Response of potato genotypes to Fny-CMV when grown at $30^{\circ} \mathrm{C}$ post-inoculation

\begin{tabular}{lccccccc}
\hline \hline \multirow{2}{*}{ Potato Genotype } & \multicolumn{2}{c}{ Local Infection (inoculated leaves) } & & \multicolumn{3}{c}{ Systemic Infection (uninoculated leaves) } \\
\cline { 2 - 3 } & \% Infected & ELISA & SD $-/+$ & & \% Infected & ELISA & SD -/+ \\
\hline A6 & $100(3 / 3)$ & 2.41 & 0.051 & & $100(3 / 3)$ & 2.44 & 0.005 \\
Abnaki & $100(6 / 6)$ & 1.28 & 0.009 & & $100(6 / 6)$ & 1.45 & 0.003 \\
All Blue & $100(6 / 6)$ & 2.39 & 0.061 & & $100(6 / 6)$ & 1.45 & 0.006 \\
Allegany & $100(6 / 6)$ & 2.73 & 0.060 & & $100(6 / 6)$ & 1.63 & 0.007 \\
Andover & $100(6 / 6)$ & 2.10 & 0.059 & & $100(6 / 6)$ & 0.78 & 0.004 \\
Amey & $100(6 / 6)$ & 1.07 & 0.135 & & $100(6 / 6)$ & 1.23 & 0.003 \\
BelRus & $100(6 / 6)$ & 1.23 & 0.064 & & $100(6 / 6)$ & 1.13 & 0.007 \\
Castile & $100(6 / 6)$ & 1.36 & 0.070 & & $100(6 / 6)$ & 1.22 & 0.071 \\
Chieftain & $100(6 / 6)$ & 1.34 & 0.028 & & $100(6 / 6)$ & 1.66 & 0.078 \\
Chippewa & $100(6 / 6)$ & 2.50 & 0.138 & & $100(6 / 6)$ & 1.61 & 0.003 \\
Kanona & $100(6 / 6)$ & 1.61 & 0.104 & & $100(6 / 6)$ & 2.23 & 0.004 \\
Katahdin & $100(6 / 6)$ & 1.55 & 0.084 & & $100(6 / 6)$ & 1.23 & 0.071 \\
La Rouge & $100(6 / 6)$ & 0.90 & 0.060 & & $100(6 / 6)$ & 1.23 & 0.004 \\
NY99 & $100(3 / 3)$ & 1.75 & 0.008 & & $100(3 / 3)$ & 0.87 & 0.003 \\
Pentland Ivory & $100(3 / 3)$ & 1.63 & 0.013 & & $100(3 / 3)$ & 1.35 & 0.002 \\
Russet Burbank & $100(6 / 6)$ & 2.34 & 0.051 & & $100(6 / 6)$ & 2.55 & 0.007 \\
Steuben & $100(3 / 3)$ & 2.42 & 0.006 & & $100(3 / 3)$ & 2.16 & 0.006 \\
Superiorn & $100(6 / 6)$ & 2.14 & 0.099 & & $100(6 / 6)$ & 1.80 & 0.006 \\
Tobacco+control & $100(2 / 2)$ & 1.66 & 0.002 & & $100(2 / 2)$ & 1.88 & 0.001 \\
Potato-control & $0(0 / 2)$ & 0.01 & 0.001 & & $0(0 / 2)$ & 0.00 & 0.003 \\
\hline
\end{tabular}

Local infection samples were taken from inoculated leaves 2 weeks post-inoculation, and systemic samples were taken from uninoculated leaves 4 weeks post-inoculation. All ELISA values are means and numbers in parentheses denote the number of infected plants over number inoculated. Tobacco + control refers to tobacco plants inoculated with Fny-CMV, and potato-control refers to potato plants mock inoculated with phosphate buffer only. SD stands for standard deviation.

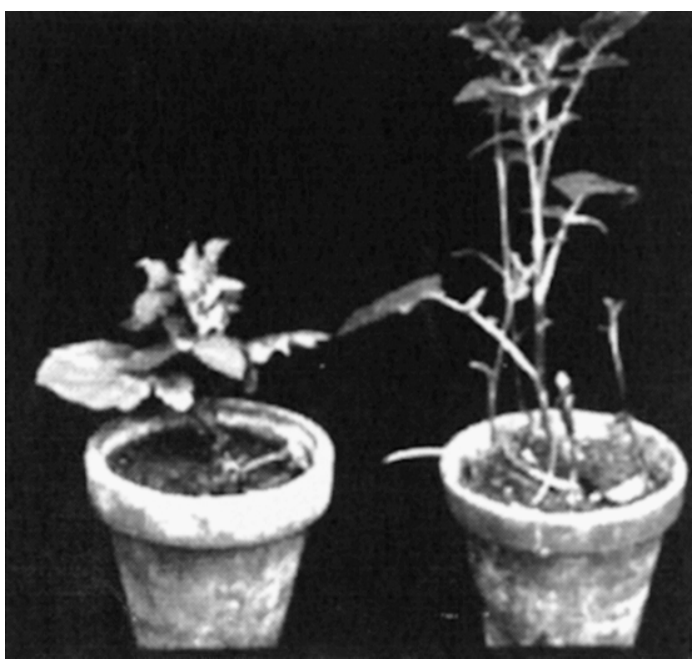

Fig. 1. CMV resistant cultivar Katahdin, inoculated with Fny-CMV and grow at either $24^{\circ} \mathrm{C}$ or $30^{\circ} \mathrm{C}$. The plant on the left was grown at $30^{\circ} \mathrm{C}$ postinoculation and shows severe stunting and systemic mosaic symptoms following CMV infection. The plant on the right was grown at $24^{\circ} \mathrm{C}$ postinoculation and does not exhibit disease symptoms and CMV could not be detected in non-inoculated leaves by ELISA.

systemically infected by Fny-CMV (subgroup I) after 4 weeks, whereas the same genotypes did not show systemic
Table 6. Summary of CMV strain specificity for the eight potato genotypes susceptible to systemic infection at $24^{\circ} \mathrm{C}$

\begin{tabular}{lccc}
\hline \multirow{2}{*}{ Potato Genotype } & \multicolumn{2}{c}{ Subgroup I } & Subgroup II \\
\cline { 2 - 4 } & Pf-CMV & Fny-CMV & A9-CMV \\
\hline A6 & $\mathrm{R}$ & $\mathrm{S}$ & $\mathrm{nd}$ \\
Allegany & $\mathrm{R}$ & $\mathrm{S}$ & $\mathrm{S}$ \\
All Blue & $\mathrm{nd}$ & $\mathrm{S}$ & $\mathrm{R}$ \\
Andover & $\mathrm{R}$ & $\mathrm{S}$ & $\mathrm{S}$ \\
Atlantic & $\mathrm{nd}$ & $\mathrm{S}$ & $\mathrm{R}$ \\
Katahdin & $\mathrm{nd}$ & $\mathrm{R}$ & $\mathrm{S}$ \\
2x (V-3) 30 & $\mathrm{R}$ & $\mathrm{S}$ & $\mathrm{R}$ \\
Acl 7-8 & $\mathrm{S}$ & $\mathrm{nd}$ & $\mathrm{R}$ \\
\hline
\end{tabular}

$\mathrm{S}$ denotes susceptibility to systemic infection, $\mathrm{R}$ denotes resistance, and nd stands for not done.

infection by A9-CMV (subgroup II) until 8 weeks postinoculation. Such differences may be due to slower rates of A9-CMV replication and/or movement compared to FnyCMV. For systemic infections to occur in plants, viruses must be able to enter and exit bundle sheath cells, phloem parenchyma, companion cells, and sieve elements (Carrington et al. 1996, Lucas 1995). It has been shown that the 3a protein and coat protein encoded by CMV were involved in long distance virus movement (Blackman et al. 1998, Kaplan et al. 1997). CMV also codes for a host sensitive long distance movement protein, the $2 \mathrm{~b}$ protein (Scholthof et al. 1995). In response, resistant host plants often have genes that resist and/or prevent long distance virus movement either at the 
point of entry or exit of cells (Carrington et al. 1996, Goodrick et al. 1991). But, even when these genes are present, they may or may not be expressed or be effective under certain circumstances, such as elevated growth temperatures.

Such a suppression of potato natural resistance to CMV may be involved in the effect observed in this report, when $\mathrm{CMV}$ inoculated potatoes were grown at $30^{\circ} \mathrm{C}$. Initially, 13 of the 18 potato genotypes tested were resistant to systemic $\mathrm{CMV}$ infection when the plants were grown at $24^{\circ} \mathrm{C}$ p.i., even though all 18 supported virus replication in inoculated leaves. In contrast, all 18 potato genotypes became systemically infected when inoculated plants were grown at $30^{\circ} \mathrm{C}$.

Inheritance of A9-CMV resistance was studied by others in NY99 progeny (tetraploid) which showed quantitative segregation at $24^{\circ} \mathrm{C}$ (Dr. K.N. Watanabe, personal communication). A recent report proposed that CMV resistance in diploid potato can be explained by three different mechanism: 1) virus was restricted in inoculated leaves at low temperature $\left(18^{\circ} \mathrm{C}\right)$ but virus overcomes at high temperature, and it is controlled by a single locus from $2 x(\mathrm{~V}-2) 7 ; 2)$ resistance controlled by duplicate loci and depended on plant age or physiological stage from IvP35; 3) resistance was induced with induction of autonomous cell death from 87HW13.7 at high temperature (Valkonen and Watanabe 1999). Explanation for this loss of resistance include the movement of host factors, which can prevent virus movement at lower temperatures, but become inactivated at higher temperatures; or that the higher temperature increases CMV replication and the higher virus titers in the plant overwhelms the host plant resistance. While the precise factors involved in the temperature sensitive nature of potato resistance to $\mathrm{CMV}$ remain unknown, it appears that CMV could negatively affect potato crops grown in warm climates.

In summary, our data demonstrated that all three strains of CMV could replicate in inoculated leaves of potato, but that most potato genotypes tested were resistant to systemic infection when grown at $24^{\circ} \mathrm{C}$. Of those potato genotypes susceptible to systemic infection, variations in host response and virus strain specificity were observed. The resistance to CMV systemic infection expressed by potato genotypes grown at $24^{\circ} \mathrm{C}$ p.i., could be overcome when inoculated plants were grown at $30^{\circ} \mathrm{C}$. These observations suggest that, although potatoes can support localized CMV replication, most potato genotypes have mechanisms that inhibit the systemic spread of the virus, but these mechanisms can be compromised by factor such as CMV strain and temperature. Further investigations into the genetics and molecular biology of the natural resistance of potato to CMV could help us to understand how CMV is localized in potato, information that could be useful in other, susceptible, solanaceous crops.

From an agricultural perspective these data also suggest that CMV could pose a threat to potato crops grown in warmer climates or in moderate climates during periods of elevated temperature particularly in semi-tropical and high land tropical areas. The major effect on agriculture, however, is indirect effect of infected potato as an inoculum source to other crops that can be severely infected and damaged such as cucurbits and tomato.

\section{Acknowledgments}

We would like to thank Laura Miller for her technical assistance and suggestions, and acknowledge the Turkish Ministry of Education for sponsoring F. Celebi-Toprak.

\section{Literature Cited}

Blackman,L.K., P.Bovink, S.Santa Cruz, P.Paulkaitis and K.J.Oparka (1998) The movement protein of cucumber mosaic virus traffics into sieve elements in minor veins of Nicotiana clevelandii. Plant Cell 10: 525-537.

Banik,M.T. and T.A.Zitter (1990) Determination of cucumber mosaic virus titer in muskmelon by enzyme linked immunosorbent assay and correlation with aphid transmission. Plant Disease 74: 727-734.

Carrington,J.C., K.D.Kasschau, S.K.Mahajan and M.C.Schaad (1996) Cell-to-cell and long distance transport of viruses in plants. Plant Cell 8: 1669-1681.

Celebi,F., P. Russo, K. Watanabe, J.P.T. Valkonen and S.A.Slack (1998) Resistance of potato to cucumber mosaic virus appears related to localization in inoculated leaves. Amer. J. of Potato Res. 75: 195-199.

Clark,M.F. and A.N.Adams (1977) Characteristics of the microplate method of enzyme-linked immunosorbent assay for the detection of plant viruses. J. Gen. Virol. 34: 475-483.

De Boks, J.A. and J.P.H.vander Want (1987) Viruses of potatoes and seed-potato production. PUDOC, Wageningen, The Netherlands.

Goodrick,B.J., C.W.Kuhn and R.S.Hussey (1991) Restricted systemic movement of cowpea chlorotic mottle virus in soybean with nonnecrotic resistance. Phytopathology 81: 1426-1431.

Hooker, W.J. (1981) Compendium of potato diseases. American Phytopathological Society, St Paul, Minn.

Jones, R.A.C. and L.J.Latham (1996) Natural resistance to cucumber mosaic virus in lupin species. Ann. Appl. Biol. 129: 523-542.

Kaplan,I.B., A.Gal-On and P.Palukaitis (1997) Characterization of cucumber mosaic virus. III. Localization of sequences in the movement protein controlling systemic infection in cucurbits. Virology 230: 343-349.

Lucas, W.J. (1995) Plasmodesmata: intercellular channels for macromolecular transport in plant. Curr. Opin. Cell. Biol. 7: 673-680.

MacArthur,A.W. (1958) A note on the occurrence of cucumber mosaic virus in potato. Scottish Plant Breeding Station Report. p. 7576.

Nono-Womdim,R., G.Marchoux, E.Pochard, A.Palloix and K.GebreSelassie (1991) Resistance of pepper lines to the movement of cucumber mosaic virus. Phytopathology 132: 21-32.

Owen,J. and P.Palukaitis (1988) Characterization of cucumber mosaic virus, I. Molecular heterogeneity mapping of RNA 3 in eight CMV strains. Virology 166: 495-502.

Palukaitis,P., M.J.Roossinck, R.G.Dietzgen and R.I.B.Francki (1992) Cucumber mosaic virus. Adv. in Virus Res. 41: 281-348.

Pink, D.A.C. and D.G.A.Walkey (1985) Effect of temperature and light intensity on resistance in marrow (Cucurbita pepo) to cucumber mosaic virus. J. Agric. Sci. Camb. 104: 325-329.

Pound, G. and P.C.Cheo (1952) Studies on resistance to cucumber 
virus I in spinach. Phytopathology 42: 301-306.

Roossinck,M.J. and P.Palukaitis (1990) Rapid induction and severity of symptoms in zucchini squash (Cucurbita pepo) map to RNA 1 of cucumber mosaic virus. Mol. Plant-Microbe Interact. 3: 188-192.

Sangar,R.B.S. and H.O.Agrawal (1986) Occurrence of cucumber mosaic virus on potato in India. Indian Phytopathology 39: 503 505.

Scholthof,H.B., K.B.C.Scholthof, M.Kikkert and A.O.Jackson (1995) Tomato bushy stunt virus spread is regulated by two nested genes that function in cell-to-cell movement and hostdependent systemic invasion. Virology 213: 425-438.

Shahwan,I.M., O.A.Abdalla and M.A.Al-Saleh (1997) Virus in the northern potato producing regions of Saudi Arabia. Plant
Pathology 46: 91-94.

Somerville,P.A., R.N.Campbell, D.H.Hall and A.Rowhani (1987) Natural infection of potatoes (Solanum tuberosum) by a legume strain of cucumber mosaic virus. Plant Disease 71: 18-20.

Valkonen,J.P.T., S.A.Slack and K.N.Watanabe (1995) Resistance to cucumber mosaic virus in potato. Ann. Appl. Biol. 126: 143151.

Valkonen,J.P.T. and K.N.Watanabe (1999) Autonomous cell death, temperature sensitivity and the genetic control associated with resistance to cucumber mosaic virus (CMV) in diploid potatoes (Solanum spp.). Theor. Appl. Genet. 99: 996-1005.

Watterson,J.C. (1993) Development and breeding for resistance to pepper and tomato viruses. In "Resistance to viral disease of vegetables” KyleM.M. (eds.), Timer Press. Ore. p. 80-101. 